04.1

\title{
Воздействие импульсного тлеющего разряда атмосферного давления на алюминиевые пленки нанометровой толщины
}

\author{
(C) О.А. Емельянов, А.П. Плотников, Е.Г. Феклистов \\ Санкт-Петербургский политехнический университет Петра Великого, Санкт-Петербург, Россия \\ E-mail: oaemel2@gmail.com
}

Поступило в Редакцию 4 сентября 2020 г.

В окончательной редакции 26 ноября 2020 г.

Принято к публикации 2 декабря 2020г.

\begin{abstract}
Исследовано воздействие положительного импульсного коронного разряда на поверхность тонкопленочного катода в воздухе атмосферного давления для промежутков $2-8 \mathrm{~mm}$ при напряжении $5-15 \mathrm{kV}$ с частотой следования импульсов $10-15 \mathrm{kHz}$, амплитудой и длительностью импульса тока $10-20 \mathrm{~mA}$ и $300-500 \mathrm{~ns}$ соответственно. Показано, что при относительно малых средних токах 20-50 $\mu$ А вблизи катода разряд трансформируется в тлеющий. Вследствие контрагирования разряда на поперечном масштабе порядка $1 \mu \mathrm{m}$ джоулев разогрев формируемого катодного слоя может достигать величин порядка $1000 \mathrm{~K}$ и вызывать локальную эрозию поверхности катода. Указанный механизм необходимо учитывать при анализе эффектов взаимодействия плазмы разряда с биологическими объектами.
\end{abstract}

Ключевые слова: тлеющий разряд атмосферного давления, холодная плазма, катодное пятно, стример.

DOI: 10.21883/PJTF.2021.06.50752.18539

Коронный разряд (КР) нашел широкое применение в электрофильтрах, плазмохимических реакторах синтеза озона, ионизаторах воздуха и других устройствах, где в сантиметровых разрядных промежутках рабочие напряжения коронирующих электродов могут достигать $100 \mathrm{kV}$. В последние годы достигнуты перспективные результаты применения КР в сравнительно малых (миллиметровых) масштабах, например, при конструировании систем охлаждения приборов микроэлектроники, контроля вредных выбросов; КР эффективно используется для плазменного заживления ран, инактивации различных бактерий, вирусов и других патогенных факторов [1-5]. В указанных случаях рабочие напряжения составляют единицы-десятки киловольт, при этом средний ток КР находится в диапазоне 10-100 $\mu \mathrm{A}$. Общепринято, что биологические эффекты холодной плазмы коронного разряда связаны с генерацией химически активных соединений [4], а не с термическим воздействием, поскольку в классическом представлении разогрев стримерного канала составляет 5-10 K [6]. Этот результат получен в предположении, что характерный размер головки стримера $R_{s t r}$ в условиях пробоя коротких воздушных промежутков составляет 0.1-1 mm [7,8]. Исследованиям развития положительного стримера посвящено значительное число публикаций, но в большинстве случаев в них рассмотрены процессы формирования и развития разряда в объеме разрядного промежутка [9]. Между тем взаимодействию стримера с поверхностью катода посвящено довольно ограниченное число работ. Однако из общих соображений $[6,10-12]$ ясно, что по достижении стримером поверхности катода в зоне контакта возникает режим импульсного тлеющего разряда атмосферного давления (ТРАД). В воздухе атмосферного давления толщина катодного слоя $d_{c}$ для алюминиевых электродов составляет $\sim 2-3 \mu \mathrm{m}$ и соответствует катодному падению потенциала $U_{c}=229 \mathrm{~V}$. Даже для упомянутых характерных размеров $R_{s t r}$ объемная плотность тепла в катодном слое $Q_{V}=j U_{c} / d_{c}$, где $j=I / \pi R_{s t r}^{2}$, по порядку может составить значительную величину $\sim 10^{8} \mathrm{~W} / \mathrm{m}^{3}$, что может вызвать локальную эрозию катода. В ряде последних работ сообщается о мультиканальном характере разряда, который представляет собой скопление около 100 и более каналов микронного диаметра с размером $R_{s t r} \sim 0.1-10 \mu \mathrm{m}[13,14]$. Эти результаты получены с использованием скоростного теневого фотографирования, а также на основе анализа эрозионных кратеров (автографов) на поверхности катода и соответствуют разрядным токам на уровне десятков-сотен ампер. В нашем случае амплитуда тока не превышает нескольких десятков миллиампер, поэтому интенсивность свечения разряда будет на много порядков (примерно в квадрат отношения значений токов) меньше. В этих условиях исследование динамики тонкой структуры слаботочного наносекундного стримерного разряда весьма затруднительно. Тем не менее вполне можно использовать метод оптического исследования автографов разряда на тонкопленочном катоде нанометровых толщин [15] с целью определения характера и кинетики процесса эрозии. В качестве прозрачной подложки можно использовать полимерную пленку, которая по основным теплофизическим характеристикам не сильно отличается от биологических тканей. С одной стороны, малая толщина катода локально чувствительна к эрозионным процессам, а с другой - практически не оказывает влияния на тепловое состояние подложки. Важно отметить, что импульсы тока при разряде на эпидермис человека имеют те же параметры [5], что и в настоящем эксперименте. Таким образом, металлизиро- 


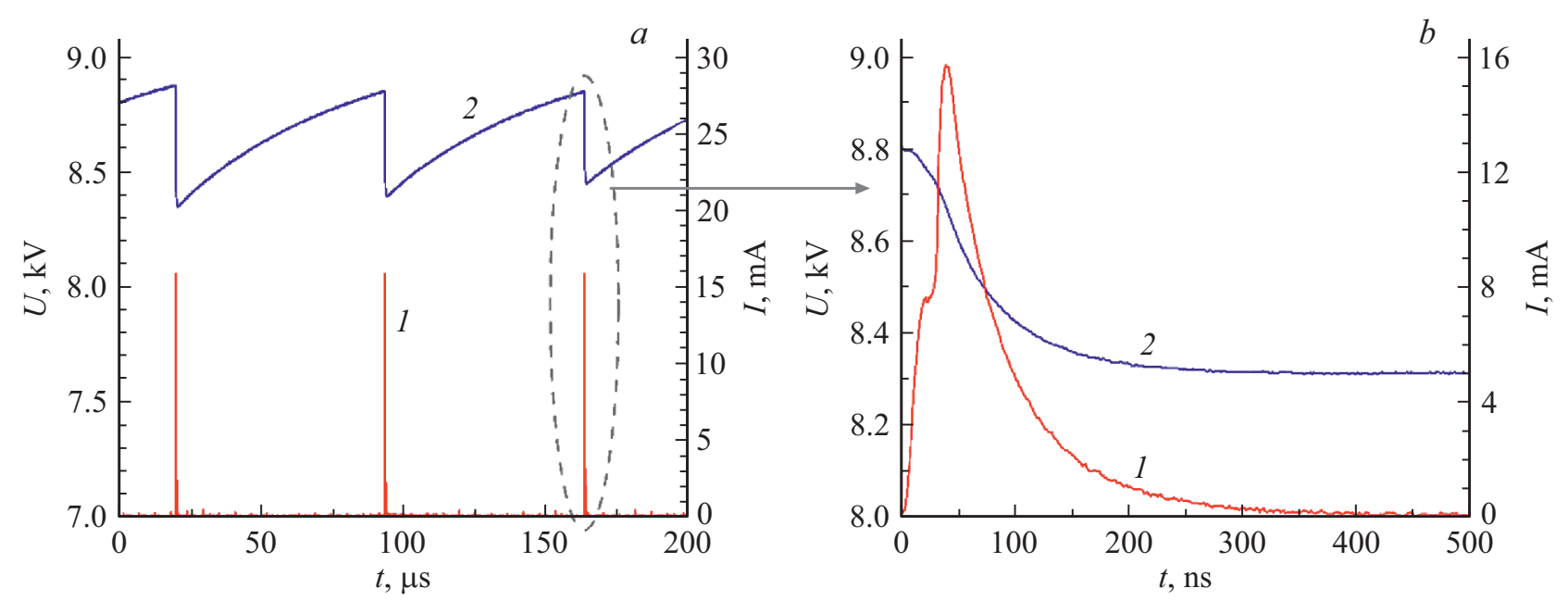

Рис. 1. Осциллограммы тока (1) и напряжения (2). Воздушный зазор $8 \mathrm{~mm}$, напряжение $9 \mathrm{kV}$, амплитуда импульсов тока $16 \mathrm{~mA}$, частота следования импульсов $13 \mathrm{kHz}$.

ванная полимерная пленка может служить модельным образцом при исследовании воздействия импульсного периодического положительного коронного разряда на поверхность биологических тканей. Эрозия катода может быть вызвана рядом механизмов, таких как электрический взрыв проводника, микродуговые процессы, катодное распыление, разогрев катодного слоя ТРАД. Для коронного слаботочного разряда анализа роли указанных механизмов в литературе нам найти не удалось. Поэтому в работе рассматривается задача выяснения возможных механизмов эрозии катода под воздействием импульсного периодического положительного коронного разряда наносекундной длительности в миллиметровых промежутках при средних токах $10-100 \mu \mathrm{A}$ и рабочих напряжениях $5-15 \mathrm{kV}$, характерных не только для биомедицинских, но и для ряда технических приложений.

Анодом служила стальная игла с характерным диаметром $0.8 \mathrm{~mm}$ и радиусом закругления $\sim 40 \mu \mathrm{m}$. К игле прикладывался потенциал $U_{0} \sim 5-15 \mathrm{kV}$ через ограничительный резистор $R_{\text {ext }}=20-96 \mathrm{M} \Omega$. Катод подсоединялся к земле высоковольтного источника через низкоиндуктивный токовый шунт $R_{s h}=43 \Omega$. Величина воздушного зазора варьировалась от 2 до $8 \mathrm{~mm}$.

На рис. $1, b$ представлены три фазы газоразрядного процесса. Первая стадия длится $\sim 10 \mathrm{~ns}$ и обусловлена распространением катодонаправленного стримера. Вторая стадия занимает $\sim 100 \mathrm{~ns}$ и сопровождается снижением напряжения на зазоре до уровня погасания $U_{e x}$. В третьей фазе емкость воздушного промежутка заряжается от источника напряжения за несколько десятков микросекунд и определяет частоту процесса (рис. 1,a).

На рис. 2, а представлена фотография интегрального свечения разряда при экспозиции кадра $1 \mathrm{~s}$, которая соответствует моменту времени выдержки объекта $t=100 \mathrm{~s}$. Отчетливо видны зона разрушенной металлизации (ЗРМ) приблизительно круглой формы и ансамбль множества катодных пятен тлеющего разряда.
Использование метода автографов позволило оценить характерные размеры стримерного канала и проследить динамику разрушения тонкого металлического слоя. На рис. 2, $b, c$ представлены фотографии динамики разрушения алюминиевой пленки в ходе эксперимента. С ростом продолжительности воздействия разряда ЗРМ радиально расширяется вследствие разрушения края металлизации. Площадь ЗРМ линейно растет с течением времени и пропорциональна прошедшему заряду. Увеличенная фотография (рис. $2, d$ ) свидетельствует о минимальном характерном диаметре ЗРМ $D=2 R_{s}$ порядка $1 \mu \mathrm{m}\left(R_{s}-\right.$ радиус катодного пятна), что подтверждается косвенным расчетом площади элементарного пятна от воздействия единичного стримера с помощью известных частоты и времени экспозиции разряда.

Рассмотрим возможные механизмы энергетического воздействия стримера ТРАД на поверхность катода. Оценим возможность разрушения тонкой алюминиевой пленки в результате электрического взрыва проводника за время одиночного импульса тока $\tau_{\text {pulse }} \sim 400-500 \mathrm{~ns}$. Максимальная плотность тока имеет место на внутренней кольцевой поверхности пятна площадью $2 \pi R_{s} d$. Полагая форму импульса разрядного тока близкой к экспоненциальной с амплитудой $I_{m}$ и характерным временем спада $\tau \sim 100$ ns (рис. $1, b$ ), для интеграла действия тока получаем

$$
\begin{aligned}
h_{a} & =\int_{0}^{\tau_{e x}} j^{2} d t \approx \int_{0}^{\tau_{\text {pulse }}}\left[\frac{I(t)}{2 \pi R_{s} d}\right]^{2} d t \approx\left[\frac{I_{m}}{2 \pi R_{s} d}\right]^{2} \frac{\tau}{2} \\
& =2 \cdot 10^{15} \mathrm{~A}^{2} /\left(\mathrm{m}^{4} \cdot \mathrm{s}\right),
\end{aligned}
$$

что на два порядка меньше, чем требуется для электрического взрыва проводника [16]. Эволюция катодного пятна импульсного ТРАД к дуговой форме затруднительна по ряду соображений. Переход коронного разряда в тлеющую форму рассматривался в [17], 

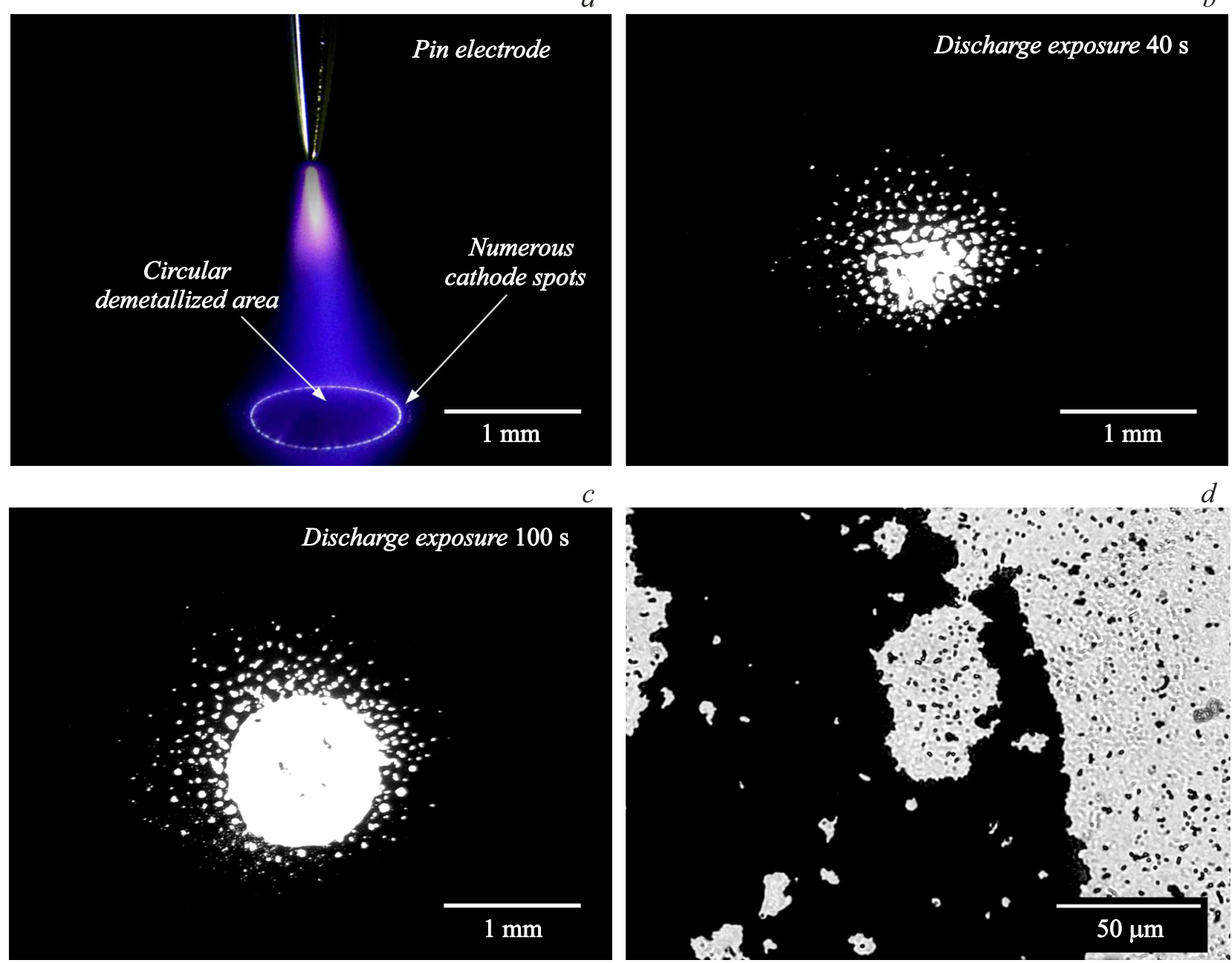

Рис. 2. Фотографии интегрального свечения разряда $(a)$ и разрушения металлизации для двух времен действия разряда $(b, c)$, а также увеличенный фрагмент периферии зоны разрушения для $100 \mathrm{~s}(d)$. Воздушный зазор $8 \mathrm{~mm}$, напряжение $9 \mathrm{kV}$, амплитуда импульсов тока $16 \mathrm{~mA}$, частота следования импульсов $13 \mathrm{kHz}$.

где время формирования катодного пятна оценивалось на уровне нескольких десятков наносекунд и характер пятна не соответствовал стандартным характеристикам дуговой формы, прежде всего по величине минимального тока на катоде $(0.1-1 \mathrm{~A})$. Кроме того, известные экспериментальные результаты исследования переходов корона-тлеющий разряд-дуга в сопоставимых условиях требуют для существования дугового разряда энергии в импульсе $W_{\text {pulse }}$ несколько сотен $\mu \mathrm{J}$. В нашем случае рассчитанные значения $W_{\text {pulse }}$ лежат в пределах 5-20 $\mu \mathrm{J}$ для всех исследованных режимов, что соответствует режиму тлеющего разряда [12]. Механизмы, связанные с катодным распылением металла ионами, также маловероятны. Поскольку давление $p=n k T_{g}(n-$ концентрация молекул воздуха, $k$ - постоянная Больцмана, $T_{g}$ - температура газа) сохраняется, длина свободного пробега ионов $\propto T_{g} / T_{0}$ за счет нагрева может вырасти до величины порядка $0.2-0.3 \mu \mathrm{m}$. С учетом приведенного давления размер катодного слоя увеличится также до величины $\sim 10-15 \mu \mathrm{m}$ и напряженность электрического поля в слое $E_{c}$ составит величину $\sim 20-15 \mathrm{~V} / \mu \mathrm{m}$. В катодном слое ТРАД, где с учетом нагрева прикатодной области длина свободного пробега ионов $\lambda$ возрастает в несколько раз, энергия ионов может достигать величины $W_{i}=e E_{c} \lambda \sim 5-10 \mathrm{eV}$ ( $e-$ элементарный заряд). Указанные значения $W_{i}$ находятся ниже порога заметного катодного распыления алюминия $[10,18]$. Известно, что низкотемпературная плазма используется в микроэлектронике для травления, где скорости травления составляют несколько $\mu \mathrm{m} / \mathrm{min}$. В наших экспериментах скорость удаления металла с поверхности полимера достигает $\sim 0.1 \mathrm{~m} / \mathrm{s}$, поэтому химическая форма разрушения также не реализуется. Температуру перегрева в катодном слое относительно окружающей $T_{0}=300 \mathrm{~K}$ можно оценить по порядку как $\Delta T_{g} \approx Q_{v} \tau / \rho C_{P} \sim 1900 \mathrm{~K}$, где $\rho$ и $C_{P}-$ соответственно известные значения плотности и теплоемкости воздуха. С учетом динамики контрагирования зоны фронта стримера в катодное пятно 
за характерное время 10-20 ns [17] среднюю величину пятна $\langle R\rangle$ можно оценить на уровне $0.1 R_{s t r}$. Тогда нагрев поверхности $T_{S}$ в одном импульсе с учетом отвода тепла в полимер к концу действия импульса можно оценить как

$$
T_{S}=\frac{I_{m}}{2 \pi\langle R\rangle^{2} \lambda_{P P}} U_{C} \sqrt{\frac{\lambda_{P P}}{\pi \rho_{P P} C_{P P}} \tau}+T_{0},
$$

где $\rho_{P P}, \lambda_{P P}$ и $C_{P P}-$ соответственно известные значения плотности, коэффициента теплопроводности и теплоемкости полипропилена. Для единичного импульса тока $T_{S}$ составляет значительную величину $\sim 1100 \mathrm{~K}$, но по достижении этого уровня произойдет разрушение приповерхностного слоя полимерной подложки и алюминиевой пленки из-за взрывного вскипания полипропилена и плавления алюминия при уровне температуры $\sim 1000 \mathrm{~K}$, который достигается на спаде импульса тока при временах 15-20 ns от максимума импульса.

Таким образом, показано, что воздействие импульсного периодического положительного разряда наносекундной длительности на катод по существу обусловлено возникновением импульсного ТРАД. Разогрев формируемого катодного слоя на поперечном масштабе контрагирования разряда порядка $1 \mu \mathrm{m}$ вызывает локальную эрозию поверхности катода. Указанное обстоятельство следует учитывать при анализе эффектов взаимодействия плазмы разряда с биологическими объектами при инактивации различных бактерий и лечении ран $[4,5,19]$.

\section{Финансирование работы}

Работа поддержана проектом Academic Excellence Project 5-100 СПбПУ Петра Великого.

\section{Конфликт интересов}

Авторы заявляют, что у них нет конфликта интересов.

\section{Список литературы}

[1] Ю.К. Стишков, А.В. Самусенко, И.А. Ашихмин, УФН, 188 (12), 1331 (2018).

[2] A. Abahazem, A. Mraihi, N. Merbahi, M. Yousfi, O. Eichwald, IEEE Trans. Plasma Sci., 39 (11), 2230 (2011).

[3] M.J. Johnson, R. Tirumala, D.B. Go, J. Electrostat., 74, 8 (2015).

[4] E. Sysolyatina, A. Mukhachev, M. Yurova, M. Grushin, V. Karalnik, A. Petryakov, N. Trushkin, S. Ermolaeva, Yu. Akishev, Plasma Process. Polym., 11, 315 (2014).

[5] О.А. Емельянов, Н.О. Петрова, Н.В. Смирнова, М.В. Шемет, Письма в ЖТФ, 43 (16), 30 (2017).

[6] Ю.П. Райзер, Физика газового разряда (Интеллект, М., 2009).

[7] A. Luque, V. Ratushnaya, U. Ebert, J. Phys. D: Appl. Phys., 41 (23), 234005 (2008).

[8] N. Babaeva, W. Tian, M.J. Kushner, J. Phys. D: Appl. Phys., 47 (23), 235201 (2014)

[9] M. Černák, T. Hoder, Z. Bonaventura, Plasma Sources Sci. Technol., 29 (1), 013001 (2020).
[10] А.А. Кудрявцев, А.С. Смирнов, Л.Д. Цендин, Физика тлеющего разряда (Лань, СПб., 2010).

[11] В.С. Голубев, С.В. Пашкин, Тлеющий разряд повыменного давления (Наука, М., 1990).

[12] D.Z. Pai, D.A. Lacoste, C.O. Laux, J. Appl. Phys., 107 (9), 093303 (2010).

[13] К.И. Алмазова, А.Н. Белоногов, В.В. Боровков, В.С. Курбанисмаилов, Г.Б. Рагимханов, А.А. Тренькин, Д.В. Терешонок, З.Р. Халикова, Письма в ЖТФ, 46 (15), 10 (2020).

[14] А.А. Тренькин, К.И. Алмазова, А.Н. Белоногов, В.В. Боровков, Е.В. Горелов, И.В. Морозов, С.Ю. Харитонов, ЖТФ, 91 (2), 255 (2021).

[15] И.Г. Кесаев, Катодные процессы электрической дуги (Наука, М., 1968).

[16] В.И. Орешкин, С.А. Баренгольц, С.А. Чайковский, ЖТФ, 77 (5), 108 (2007),

[17] Yu. Akishev, V. Karalnik, I. Kochetov, A. Napartovich, N. Trushkin, Plasma Sources Sci. Technol., 23 (5) 054013 (2014).

[18] Распыление твердых тел ионной бомбардировкой, под ред. Р. Бериша (Мир, М., 1984), т. 1.

[19] O.A. Emelyanov, E.G. Feklistov, N.V. Smirnova, K.A. Kolbe, E.V. Zinoviev, M.S. Asadulaev, A.A. Popov, A.S. Shabunin, K.F. Osmanov, in Proc. of the Int. Conf. on advances and applications in plasma physics (AAPP 2019), ed. by M. Tendler, V. Rozhansky, P. Goncharov, A. Kravchuk. AIP Conf. Proc., 2179 (1), 20006 (2019). DOI: 10.1063/1.5135479 